\title{
Use of non-steroidal anti-inflammatory drugs and risk of breast cancer: The Spanish Multi-Case-control (MCC) study
}

Trinidad Dierssen-Sotos ${ }^{1,2^{*}}$, Inés Gómez-Acebo ${ }^{1,2}$, María de Pedro ${ }^{3}$, Beatriz Pérez-Gómez ${ }^{1,4,5}$, Sonia Servitja ${ }^{6,7}$, Víctor Moreno ${ }^{1,8}$, Pilar Amiano 1,9, Tania Fernandez-Villa ${ }^{10,11}$, Aurelio Barricarte ${ }^{12,13}$, Adonina Tardon 1,14, Marian Diaz-Santos ${ }^{15,16}$, Rosana Peiro-Perez ${ }^{1,17}$, Rafael Marcos-Gragera ${ }^{18}$, Virginia Lope ${ }^{1,4,5}$, Esther Gracia-Lavedan 1,19,20, M. Henar Alonso 1,8, Maria Jesus Michelena-Echeveste ${ }^{21}$, Andrés Garcia-Palomo ${ }^{22}$, Marcela Guevara 1,12,13, Gemma Castaño-Vinyals 1,19,20,23, Nuria Aragonés ${ }^{1,4,5}$, Manolis Kogevinas 1,19,20, Marina Pollán ${ }^{1,4,5}$ and Javier Llorca ${ }^{1,2}$

\begin{abstract}
Background: The relationship between non-steroidal anti-inflammatory drug (NSAID) consumption and breast cancer has been repeatedly studied, although the results remain controversial. Most case-control studies reported that NSAID consumption protected against breast cancer, while most cohort studies did not find this effect. Most studies have dealt with NSAIDs as a whole group or with specific drugs, such aspirin, ibuprofen, or others, but not with NSAID subgroups according to the Anatomical Therapeutic Chemical Classification System; moreover, scarce attention has been paid to their effect on different tumor categories (i.e.: ductal/non-ductal, stage at diagnosis or presence of hormonal receptors).
\end{abstract}

Methods: In this case-control study, we report the NSAID - breast cancer relationship in 1736 breast cancer cases and 1895 healthy controls; results are reported stratifying by the women's characteristics (i.e.: menopausal status or body mass index category) and by tumor characteristics.

Results: In our study, NSAID use was associated with a $24 \%$ reduction in breast cancer risk (Odds ratio [OR] $=0.76$; $95 \%$ Confidence Interval [Cl]: 0.64-0.89), and similar results were found for acetic acid derivatives, propionic acid derivatives and COXIBs, but not for aspirin. Similar results were found in postmenopausal and premenopausal women. NSAID consumption also protected against hormone + or HER2+ cancers, but not against triple negative breast cancers. The COX-2 selectivity showed an inverse association with breast cancer (i.e. OR $<1$ ), except in advanced clinical stage and triple negative cancers.

Conclusion: Most NSAIDs, but not aspirin, showed an inverse association against breast cancer; this effect seems to be restricted to hormone + or HER2+ cancers.

Keywords: Breast cancer, Non-steroidal anti-inflammatory drug, Hormone receptor positive breast cancer, HER2 positive breast cancer, Triple negative breast cancer

\footnotetext{
* Correspondence: dierssent@unican.es

${ }^{1}$ CIBER Epidemiologia y Salud Publica (CIBERESP), Madrid, Spain

2University of Cantabria - IDIVAL, Santander, Spain

Full list of author information is available at the end of the article
} 


\section{Background}

The cyclooxygenase-prostaglandin inflammation pathway has been shown to play a relevant role in carcinogenesis, mainly via inhibition of the cyclooxigenase-2 (COX-2) isoform [1]. Experimental studies have demonstrated that COX-2 blockade inhibits breast tumor formation in mice, while its overexpression has the opposite effect [2]. Therefore, consumption of non-steroidal anti-inflammatory drugs (NSAIDs) is expected to be protective for cancer development.

Regarding breast cancer, results from epidemiological studies are inconsistent: cohort studies have reported very modest protective effects or no effect at all [3-5], while case-control studies have usually reported moderate protective effects [6-8]. Several meta-analyses have been conducted; combination of results is, however, complex because of differences in reporting of timing and dosing of NSAIDs in the studies. The most recent meta-analysis reported a $20 \%$ protective effect of NSAID especially aspirin and COX-2 inhibitors against breast cancer, which seems to be restricted to estrogen receptors $+(\mathrm{ER}+)$ or progesterone receptors $+(\mathrm{PR}+)$ tumors [9].

The number of epidemiological studies reporting results about the COX-2 inhibitors' effect on breast cancer or about NSAIDs' effect on different types of breast cancer (i.e.: $\mathrm{ER}+, \mathrm{PR}+$, Human epidermal growth factor receptor [HER2] +, triple negative) is still small and further studies are needed in order to clarify the specific effect of NSAID groups on different types of breast cancer $[8,10-12]$. In order to further investigate this issue, we report the results from a large case-control study performed in Spain.

\section{Methods}

\section{Study design and population}

The Multi Case-control (MCC-Spain) study is a population-based case-control study of common tumors in Spain and has been described elsewhere [13]. It has been carried out in 12 Spanish provinces. The recruitment included incident cases of colorectal, breast, stomach and prostate cancer or chronic lymphocytic leukemia diagnosed between September 1st, 2008 and December 31st, 2013, aged between 20 and 85 years old, and resident within the influence area of the hospital at least 6 months prior to recruitment. Cases were identified through active search that included periodical visits to the collaborating hospital departments (i.e. gynecology, oncology, general surgery, radiotherapy, and pathology departments), but only histologically confirmed incident cases of breast cancer (C50, D05.1, D05.7) with no prior history of the disease were included in this study. Ten out of 12 provinces recruited breast cancer cases and controls. Controls were selected from the general population according to age and sex distribution of the cases included in the study. In this paper, 1736 cases of breast cancer (ICD-10: C50, D05) in women and 1909 frequency-matched controls were considered.

Response rates were $71 \%$ for breast cancer and $72 \%$ for controls, with no differences in the main sociodemographic variables among those who participated and those who refused to participate. The Ethics Committees of participating hospitals approved the study protocols, and participants provided written informed consent at the time of enrollment.

\section{Data collection}

Participants were interviewed face-to-face by trained interviewers with a comprehensive epidemiological questionnaire that assessed socio-demographic information, personal and family history of cancer, anthropometric data, smoking habits, occupation, physical activity, water consumption, reproductive and medical history and medication/drugs use, family history, sun exposure, sleep habits, use of hygiene products and cosmetics, signs and symptoms. Diet was assessed with the use of a validated semi-quantitative Spanish Food Frequency Questionnaire (FFQ), which was modified to include regional products. The FFQ included 140 food items, and assessed usual dietary intake during the previous year.

Participant's weight was recorded by self-report, as estimated one year before diagnosis for cases and for controls. Body mass index (BMI) was estimated from selfreported weight and height 1 year before the diagnosis for cases and 1 year prior to the interview for controls. Similar estimates provided total energy consumption. Physical activity was recorded for all jobs and also recreational physical exercise.

Detailed information was obtained on past medical conditions and the corresponding medications used. Participants were asked about past medical history of diabetes mellitus, high blood pressure, high levels of cholesterol and triglycerides, heart attack, embolism, other cardiovascular diseases, degenerative osteoarthritis, arthritis, migraine or cephalalgia, gout, ulcerative colitis, Crohn's disease, renal calculus (nephrolithiasis or cystolithiasis), chronic obstructive pulmonary disease, asthma, bronchitis, irritable bowel syndrome, anemia, diverticulitis, celiac disease and cancer. The age at onset, the dates of diagnosis or occurrence and the type of treatment received for each condition was also registered.

\section{Drug use assessment}

Drug use was recorded by indication. For each drug, the brand name, dose and duration of exposure were recorded to identify patients with regular drug consumption ("no and occasionally" versus "yes") and the duration of consumption. The drugs were coded following the 
Anatomical Therapeutic Chemical Classification System (ATC codes) to define groups with similar mechanisms of action [14]. To be sure that participants report all drugs, a general question about the use of NSAIDs was included in order to add information that was not provided before.

All drugs indicated for the treatment of inflammatory diseases were considered. The main ATC code included in the present analysis are codes B01AC06 and N02BA01 (Aspirin) and code M01 (Antiinflammatory and antirheumatic drugs). Data were also analyzed for subgroups with codes M01AA (Butilpirazolidins), $\mathrm{M} 01 \mathrm{AB}$ (acetic acid derivatives; for instance, diclofenac, ketorolac), M01AC (Oxicams), M01AE (propionic acid derivatives; for instance ibuprofen, naproxen), M01AH (Coxibs; for instance, celecoxib), M01AX (other NSAIDs) and their combinations. Finally, as cox2 inhibition has been suggested as the putative mechanisms for NSAID protective effect on breast cancer, we performed a subgroup analysis according to level of COXselectivity. In this way, NSAIDs were grouped in cox1selective/cox2-selective according to their log [IC80 ratio (WHMA COX-2/COX-1)] [15]. NSAIDs with negative $\log$ (IC80 ratio) were considered cox2-selective (for instance, meloxicam, diclofenac, sulindac, piroxicam, niflumic acid), while NSAIDs with positive log (IC80 ratio) were considered cox1-selective (for instance: ibuprofen, naproxen, indomethacin, ketoprofen, ketorolac). As the putative protective mechanism of aspirin is not via cox-2 inhibition, we retained aspirin as an independent group.

\section{Statistical methods}

Unconditional logistic regression was used to assess the association between treatment of NSAID use and breast cancer, adjusting for age, recruitment area, education level, tobacco smoking history, BMI, family history of breast cancer, number of deliveries, age at first delivery, menarche age, and menopausal status. Stratified models were developed according to menopausal status and BMI $\left[<25 / \geq 25 \mathrm{~kg} / \mathrm{m}^{2}\right]$. The association between tumor characteristics (clinical stage, ductal/non-ductal cancer, hormone receptors, HER2 receptors and triple negative breast cancer) and NSAID consumption was studied using multinomial logistic regression. Results are reported as odds ratios (OR) with $95 \%$ confidence intervals $(\mathrm{CI})$. All reported $p$-values are two-tailed. Statistical analysis was carried out using the package Stata 12/SE (StataCorp, College Station, Tx, US).

\section{Results}

A description of the 1736 cases and 1909 controls included in this study is provided in Table 1. Significant differences are observed between cases and controls for several well known risk factors for breast cancer, including family history of breast cancer, age at menarche, and tobacco smoking. Clinical-pathological characteristics of the breast cancers are reported in Table 2; ductal cancer accounts for $85 \%$ of cases; two out of three breast cancers were diagnosed at stage I or II; more than $70 \%$ of cancers were estrogen receptors,$+ 14 \%$ were HER 2 receptors + and only $6 \%$ were triple negative breast cancers. Results on NSAID consumption breast cancer association are reported here for consumption of any NSAID, aspirin, acetic acid derivatives, propionic acid derivatives, COX-2 inhibitors (COXIBs), and other NSAIDs. We do not report results on butilpirazolidins because of the small number of women exposed to this group.

\section{NSAID consumption and breast cancer according to women's characteristics}

Results on the relationship between NSAID consumption and breast cancer overall and by menopausal status and BMI, according to women's characteristics are reported in Tables 3 and 4 for duration of use, and Additional file 1: Table S1 according to COX2/COX1 selectivity. NSAIDs as a global group protected against breast cancer $(\mathrm{OR}=$ 0.76; $95 \%$ CI: 0.64-0.89); a protective effect was also found for acetic acid derivatives, propionic acid derivatives and COXIBs, but not for aspirin, although COXIB results were based on small numbers of exposed cases and controls, hampering further analysis of their effect in specific subgroups of women. When stratifying for menopausal status, all NSAIDs, acetic acid derivatives, propionic acid derivatives and COXIBs showed a protective effect in postmenopausal women; ORs in postmenopausal women were similar or slightly lower to those in premenopausal women. P values for NSAID menopausal interaction status were higher than $0.10(p$ values not shown). The protective effect of any NSAID was independent of BMI; however, the effect varied in subgroups: acetic acid derivatives were protective in women with $\mathrm{BMI}<25 \mathrm{~kg} / \mathrm{m}^{2} \quad(\mathrm{OR}=0.54 ; 95 \% \mathrm{CI}$ : $0.31-0.93)$ but not in overweight or obese women, while propionic acid derivatives $(\mathrm{OR}=0.78$; $95 \% \mathrm{CI}$ : $0.61-1.00)$ protected only in the latter group; $\mathrm{p}$ values for BMI - NSAID interaction were non-significant. Table 4 reports the results according to the duration of NSAID consumption (never/less than 5 years/more than 5 years). It shows that most of the results described in the paragraph above had consistent dose-effect relationship: the longer the consumption, the lower the odds ratio. Additional file 1: Table S1 shows a greater protective effect of COX-2 both globally (OR $=0.66$; $95 \%$ CI: $0.48-0.90$ for COX-2 vs OR $=0.81$; $95 \%$ CI: $0.67-0.98)$ for COX-1 selectivity) and in postmenopausal women and in women with $\mathrm{BMI}<25 \mathrm{~kg} / \mathrm{m}^{2}$. 
Table 1 Main characteristics of cases and controls from the study population

\begin{tabular}{|c|c|c|c|c|}
\hline Variable & Category & Cases & Controls & $\mathrm{p}$ \\
\hline Age, mean $\pm s d$ & & $56.4 \pm 12.6$ & $59.0 \pm 13.2$ & $<0.001$ \\
\hline \multirow[t]{10}{*}{ Geographical area, n (\%) } & Asturias & $70(4.0)$ & $121(6.4)$ & \\
\hline & Barcelona & $292(16.8)$ & $380(20.1)$ & \\
\hline & Cantabria & $141(8.1)$ & $188(9.9)$ & \\
\hline & Gerona & $47(2.7)$ & $57(3.0)$ & \\
\hline & Guipuzcoa & $226(13.0)$ & $255(13.5)$ & \\
\hline & Huelva & $105(6.1)$ & $79(4.2)$ & \\
\hline & Leon & $227(13.1)$ & $202(10.7)$ & \\
\hline & Madrid & $341(19.6)$ & $365(19.3)$ & \\
\hline & Navarra & $226(13.0)$ & $181(9.6)$ & \\
\hline & Valencia & $61(3.5)$ & $67(3.5)$ & $<0.001$ \\
\hline \multirow[t]{3}{*}{ Family history of breast cancer, n (\%) } & No & $1288(75.0)$ & $1628(85.7)$ & \\
\hline & First-degree relative & $256(14.9)$ & $166(8.7)$ & \\
\hline & Second-degree relative & $174(10.1)$ & $106(5.8)$ & $<0.001$ \\
\hline \multirow[t]{4}{*}{ Educational level, n (\%) } & Less than primary school & $268(15.4)$ & $327(17.3)$ & \\
\hline & Primary school & $565(32.6)$ & $581(30.7)$ & \\
\hline & Secondary school & $573(33.0)$ & $585(30.9)$ & \\
\hline & University & $330(19.0)$ & $402(21.2)$ & 0.10 \\
\hline \multirow[t]{3}{*}{ Tobacco smoking, n (\%) } & Never smoker & $972(56.0)$ & $1141(60.2)$ & \\
\hline & Former smoker & $450(25.9)$ & $397(21.0)$ & \\
\hline & Current smoker & $314(18.1)$ & $357(18.8)$ & 0.002 \\
\hline \multirow[t]{4}{*}{ Body Mass Index $\left(\mathrm{kg} / \mathrm{m}^{2}\right), \mathrm{n}(\%)$} & $<18.5$ & $30(1.7)$ & $43(2.3)$ & \\
\hline & $18.5-24.9$ & $789(45.5)$ & $899(47.4)$ & \\
\hline & $25.0-29.9$ & $590(34.0)$ & $601(31.7)$ & \\
\hline & $\geq 30$ & $327(18.8)$ & $352(18.6)$ & 0.31 \\
\hline Energy intake (kcal/day), mean \pm sd & & $1861 \pm 644$ & $1754 \pm 566$ & $<0.001$ \\
\hline Ethanol intake ( $\mathrm{g} /$ day), mean $\pm \mathrm{sd}$ & & $6.2 \pm 11.5$ & $5.3 \pm 9.5$ & 0.01 \\
\hline Red meat intake ( $\mathrm{g} /$ day), mean $\pm \mathrm{sd}$ & & $26.9 \pm 20.2$ & $25.2 \pm 19.9$ & 0.01 \\
\hline Fruit intake (g/day), mean \pm sd & & $363 \pm 239$ & $365 \pm 222$ & 0.87 \\
\hline Vegetable intake ( $g /$ day), mean \pm sd & & $196 \pm 133$ & $198 \pm 119$ & 0.60 \\
\hline Dairy intake ( $g /$ day), mean $\pm \mathrm{sd}$ & & $321.1 \pm 177.1$ & $328.7 \pm 176.7$ & 0.24 \\
\hline Number of deliveries, mean $\pm \mathrm{sd}$ & & $1.9 \pm 1.5$ & $2.0 \pm 1.6$ & 0.03 \\
\hline \multirow[t]{2}{*}{ Menopausal status, n (\%) } & Premenopausal & $702(40.4)$ & $628(33.1)$ & \\
\hline & Postmenopausal & $1034(59.6)$ & $1267(66.9)$ & $<0.001$ \\
\hline Age at first delivery, mean $\pm s d$ & & $26.5 \pm 5.0$ & $26.5 \pm 4.7$ & 0.82 \\
\hline Age at menarche, mean $\pm s d$ & & $12.8 \pm 1.5$ & $12.9 \pm 1.5$ & 0.02 \\
\hline Age at menopause, mean \pm sd & & $48.8 \pm 5.4$ & $48.5 \pm 5.3$ & 0.18 \\
\hline Previous use of hormonal contraceptives, n (\%) & & $789(45.5)$ & $868(45.8)$ & 0.83 \\
\hline
\end{tabular}

\section{NSAID consumption and breast cancer according to} tumor characteristics

Results for subgroups of breast cancer are reported in Tables 5 and 6 (for duration of use) and Additional file 2: Table S2 (according to COX2/COX1 selectivity). The protective effect of any NSAID seemed similar in early or late clinical stages $(\mathrm{OR}=0.80 ; 95 \% \mathrm{CI}$ : 0.66-0.97 in stages $1-2$; OR $=0.74$; $95 \% \mathrm{CI}$ : $0.51-1.06$ in stages $3-4$ ), but no specific NSAID group reached statistically significant effect. Consumption of any NSAID, acetic acid derivatives and propionic acid derivatives was protective for ductal cancer $(\mathrm{OR}$ for any NSAID $=0.70$; $95 \% \mathrm{CI}$ : 
Table 2 Clinical and pathological characteristics of breast cancers

\begin{tabular}{ll}
\hline Classification & $\mathrm{N}(\%)$ \\
\hline Pathology & $1289(74.3)$ \\
Ductal & $112(6.5)$ \\
Lobular & $22(1.3)$ \\
Papilar & $20(1.2)$ \\
Coloid & $12(0.7)$ \\
Tubular & $27(1.6)$ \\
Mixed & $35(2.0)$ \\
Other & $213(12.3)$ \\
Not Available & \\
Clinical stage & $115(6.6)$ \\
0 & $604(34.8)$ \\
I & $495(28.5)$ \\
II & $182(10.5)$ \\
III & $22(1.3)$ \\
IV & $196(11.3)$ \\
Not Available & \\
Inmunohistochemistry & $992(62.5)$ \\
Progesterone & $1147(72.2)$ \\
Estrogens & $227(14.3)$ \\
HeR2 & $92(5.8)$ \\
\hline
\end{tabular}

0.58-0.84) but not for non-ductal cancer, although the $\mathrm{p}$ value for heterogeneity was non-significant for NSAID as a group or for any specific subgroup. All NSAID consumption was protective for hormone receptor + cancer (i.e.: $\mathrm{ER}+$ or $\mathrm{PR}+)(\mathrm{OR}=0.72$; $95 \% \mathrm{CI}: 0.60-0.88)$ and HER $2+$ cancers $(\mathrm{OR}=0.63 ; 95 \%$ : 0.45-0.88). Propionic acid derivatives also showed this protective effect in hormone + or HER 2 + cancers, while acetic acid derivatives showed a non-statistically significant effect $(\mathrm{OR}=0.76$; $95 \%$ CI: $0.54-1.08$ in hormone receptor + cancers and $\mathrm{OR}=0.67 ; 95 \% \mathrm{CI}: 0.36-1.24$ in HER2 receptor + cancers). Neither consumption of NSAID in general nor any specific NSAID subgroup showed a protective effect in triple negative breast cancers.

When studying the effect of length of consumption (Table 6), most associations reported above were at least as strong in patients with more than 5 years of consumption as in patients with less than 5 years.

Finally, regarding the COX-selectivity of the NSAID (Additional file 2: Table S2), the COX-2 selectivity showed an inverse association with breast cancer (i.e. $\mathrm{OR}<1$ ), except in advanced clinical stage and triple negative cancers.

\section{Discussion}

In this large case-control study, NSAID use was associated with a $24 \%$ reduction in breast cancer risk. An inverse association were observed specifically for acetic acid derivative and propionic acid derivative use, but not for aspirin consumption. There is a trend towards a stronger protective effect of NSAID in postmenopausal women, ductal cancer, and hormone receptor or HER2 receptor positive tumors. This protective effect was less pronounced in premenopausal women, non-ductal cancer, or triple negative cancer, although the small number of cases with triple negative cancer makes it difficult to reach definitive conclusions.

Regarding NSAID effect overall, our results are coherent with those reported in 10 out of 16 case-control studies [6-8, 16-22], while the remaining six studies did not show any effect [23-28]. Results from 13 cohort studies hardly support any NSAID effect on breast cancer risk; only four reported protective effects [3, 4, 29, 30], seven did not find any association [5, 31-35], and three reported an increase in breast cancer risk [36-38]. Consequently, a recent meta-analysis [9] showed a significant protective odds ratio $(\mathrm{OR}=0.82)$ when combining case-control studies, but a non-significant relative risk $(R R=0.92)$ in cohort studies. Most studies, however, did not report stratified results.

Some studies have analyzed the effect of aspirin, ibuprofen or non-aspirin NSAIDs, reporting similar results to those presented for NSAIDs in general (i.e.: protective effect in case-control studies; no effect in cohort studies) [9]. Scarce attention has been paid, however, to the effect associated with different pharmacological subgroups. According to our results, acetic acid derivatives, propionic acid derivatives and COX-2 inhibitors have a protective effect against breast cancer incidence, while aspirin has no effect at all. The absence of a significant effect of aspirin is puzzling since prior investigations have noted not only preventive effects but also therapeutic effects of aspirin against breast cancer. In this regard, aspirin consumption could be underreported in our study due to its common over-the-counter usage; as this possible underreporting would affect both cases and controls in a similar way, it would eventually lead to a bias towards the null, which would justify a negative result. This phenomenon is not to be expected in other NSAIDs as their usual consumption is by prescription.

The public health implications of the reduction in breast cancer risk when taking acetic acid and propionic acid derivatives should be highlighted as these groups account for about $80 \%$ of NSAID consumption in the Spanish population. A note of caution should be remarked on aspirin results; the percentage of people declaring aspirin consumption seems low, which could be due to a reporting bias. Study participants were asked to report the diseases they were suffering from and the drugs they had been taking for treating them and we have also asked whether they were taking any other 
Table 3 Relationship between NSAID consumption and breast cancer according to women's characteristics

\begin{tabular}{|c|c|c|c|c|c|}
\hline Population & NSAID & Unexposed controls/cases (n) & Exposed controls/Cases (n) & OR $(95 \% \mathrm{Cl})$ & $\mathrm{p}$ \\
\hline \multirow[t]{6}{*}{ All women } & NSAID (all) & $1170 / 1111$ & $739 / 625$ & $0.76(0.64-0.89)$ & 0.001 \\
\hline & Aspirin & $1807 / 1653$ & $102 / 83$ & $0.91(0.64-1.29)$ & 0.60 \\
\hline & Acetic acid derivatives & $1753 / 1620$ & $156 / 116$ & $0.75(0.55-1.01)$ & 0.06 \\
\hline & Propionic acid derivatives & $1350 / 1232$ & $559 / 504$ & $0.82(0.69-0.98)$ & 0.03 \\
\hline & cox2 inhibitors & 1891/1731 & $18 / 5$ & $0.28(0.09-0.88)$ & 0.03 \\
\hline & NSAID others & 1861/1697 & $48 / 39$ & $1.13(0.67-1.89)$ & 0.65 \\
\hline \multirow[t]{6}{*}{ Premenopausal } & NSAID (all) & $361 / 415$ & $267 / 287$ & $0.80(0.60-1.07)$ & 0.14 \\
\hline & Aspirin & $613 / 689$ & $15 / 13$ & $0.60(0.25-1.47)$ & 0.27 \\
\hline & Acetic acid derivatives & $600 / 664$ & $28 / 38$ & $0.75(0.42-1.36)$ & 0.35 \\
\hline & Propionic acid derivatives & $392 / 451$ & $236 / 251$ & $0.84(0.62-1.13)$ & 0.24 \\
\hline & cox2 inhibitors & $626 / 701$ & $2 / 1$ & - & - \\
\hline & NSAID others & $618 / 693$ & $10 / 9$ & $1.26(0.41-3.9)$ & 0.69 \\
\hline \multirow[t]{6}{*}{ Postmenopausal } & NSAID (all) & $804 / 696$ & $462 / 338$ & $0.69(0.56-0.86)$ & $<0.001$ \\
\hline & Aspirin & $1180 / 964$ & $86 / 70$ & $0.99(0.68-1.46)$ & 0.98 \\
\hline & Acetic acid derivatives & $1142 / 956$ & $124 / 78$ & $0.72(0.50-1.03)$ & 0.07 \\
\hline & Propionic acid derivatives & $953 / 781$ & $313 / 253$ & $0.78(0.62-0.98)$ & 0.03 \\
\hline & cox2 inhibitors & $1250 / 1030$ & $16 / 4$ & - & - \\
\hline & NSAID others & $1228 / 1004$ & $38 / 30$ & $1.05(0.58-1.90)$ & 0.86 \\
\hline \multirow[t]{6}{*}{$\mathrm{BMl}<25$} & NSAID (all) & $578 / 537$ & $364 / 282$ & $0.73(0.57-0.94)$ & 0.02 \\
\hline & Aspirin & $901 / 794$ & $41 / 25$ & $0.74(0.40-1.35)$ & 0.32 \\
\hline & Acetic acid derivatives & $883 / 783$ & $59 / 36$ & $0.54(0.31-0.93)$ & 0.03 \\
\hline & Propionic acid derivatives & $656 / 575$ & $286 / 244$ & $0.86(0.66-1.13)$ & 0.27 \\
\hline & cox2 inhibitors & $932 / 816$ & $10 / 3$ & - & - \\
\hline & NSAID others & $919 / 806$ & $23 / 13$ & $0.98(0.42-2.31)$ & 0.97 \\
\hline \multirow[t]{6}{*}{$\mathrm{BMI}>25$} & NSAID (all) & $592 / 574$ & $375 / 343$ & $0.76(0.60-0.95)$ & 0.02 \\
\hline & Aspirin & $906 / 859$ & $61 / 58$ & $1.01(0.65-1.56)$ & 0.96 \\
\hline & Acetic acid derivatives & $870 / 837$ & $97 / 80$ & $0.81(0.56-1.18)$ & 0.27 \\
\hline & Propionic acid derivatives & $694 / 657$ & $273 / 260$ & $0.78(0.61-1.00)$ & 0.05 \\
\hline & cox2 inhibitors & 959/915 & $8 / 2$ & - & - \\
\hline & NSAID others & $942 / 891$ & $25 / 26$ & $1.24(0.64-2.41)$ & 0.52 \\
\hline
\end{tabular}

OR Odds ratio adjusted for age, recruitment area, education level, tobacco smoking history, BMI family history of breast cancer, number of deliveries, age at first delivery, menarche age, and menopausal status. $\mathrm{Cl}$ confidence interval

NSAID not reported before. It is possible that some people might not consider aspirin to be a drug, so failing to declare its usage.

Most studies did not analyze NSAID effect on several types of breast cancer. According to our results, the inverse association of NSAID with breast cancer is more pronounced in postmenopausal cancers, ductal cancer, and hormone receptor or HER2 receptor positive tumors. This effect increases in women treated with COX-2 inhibitors, especially in early clinical stage, postmenopausal cancers and receptor positive tumors. The putative pathway for the NSAID protective effect is via COX inhibition. High levels of prostaglandins, derived from the activation of the COX/prostaglandin pathway, contribute to carcinogenesis in various ways (increase in mitogenesis, mutagenesis, angiogenesis, metastasis formation, inhibition of apoptosis, and immunosuppression) [38-40]. Constitutive expression of the COX-2 gene and sustained biosynthesis of $\mathrm{PGE}_{2}$ seem to be associated with the initiation and promotion of breast carcinogenesis [41]. In a prospective study, COX-2 expression in biopsy specimens from women with atypical breast hyperplasia was a significant predictor of breast cancer risk [42]; COX-2 overexpression, therefore, seems to constitute an early event in breast carcinogenesis, which makes COX-2 a potential cancer biomarker and a key target for breast cancer prevention [43]. Unfortunately, cardiovascular toxicity attributed to COX-2 inhibitors has partially decreased 
Table 4 Relationship between length of non-steroideal anti-inflammatory drug consumption and breast cancer, according to women's characteristics

\begin{tabular}{|c|c|c|c|c|c|c|}
\hline \multirow[t]{2}{*}{ Population } & \multirow[t]{2}{*}{ NSAID } & \multirow{2}{*}{$\begin{array}{l}\text { No consumption } \\
\text { Controls/cases (n) }\end{array}$} & \multicolumn{2}{|l|}{ Consumption $\leq 5 y$} & \multicolumn{2}{|l|}{ Consumption $>5 y$} \\
\hline & & & Controls/cases (n) & OR $(95 \% \mathrm{Cl})$ & Controls/cases (n) & OR $(95 \% \mathrm{Cl})$ \\
\hline \multirow[t]{5}{*}{ All women } & NSAID (all) & $1171 / 1111$ & $484 / 445$ & $0.81(0.67-0.98)$ & $255 / 180$ & $0.64(0.50-0.83)$ \\
\hline & Aspirin & $1808 / 1653$ & $79 / 70$ & $0.99(0.67-1.46)$ & $23 / 13$ & $0.65(0.31-1.38)$ \\
\hline & Acetic acid derivatives & $1754 / 1620$ & $113 / 86$ & $0.75(0.53-1.06)$ & $43 / 30$ & $0.75(0.42-1.32)$ \\
\hline & Propionic acid derivatives & $1351 / 1232$ & $380 / 364$ & $0.86(0.71-1.06)$ & $179 / 140$ & $0.73(0.55-0.97)$ \\
\hline & NSAID others & $1862 / 1697$ & $33 / 35$ & $1.47(0.83-2.60)$ & $15 / 4$ & - \\
\hline \multirow[t]{5}{*}{ Premenopausal } & NSAID (all) & $361 / 415$ & $162 / 187$ & $0.82(0.59-1.13)$ & $105 / 100$ & $0.78(0.52-1.17)$ \\
\hline & Aspirin & $613 / 689$ & $12 / 12$ & $0.72(0.27-1.95)$ & $3 / 1$ & - \\
\hline & Acetic acid derivatives & $600 / 664$ & $21 / 27$ & $0.68(0.35-1.34)$ & $7 / 11$ & $1.02(0.31-3.32)$ \\
\hline & Propionic acid derivatives & $392 / 461$ & $146 / 167$ & $0.85(0.61-1.19)$ & $90 / 84$ & $0.81(0.52-1.25)$ \\
\hline & NSAID others & 618/693 & $6 / 8$ & $2.38(0.63-9.00)$ & $4 / 1$ & - \\
\hline \multirow[t]{5}{*}{ Postmenopausal } & NSAID (all) & $805 / 696$ & $312 / 258$ & $0.77(0.61-0.98)$ & $150 / 80$ & $0.53(0.38-0.75)$ \\
\hline & Aspirin & $1181 / 964$ & $66 / 58$ & $1.08(0.70-1.66)$ & $20 / 12$ & $0.74(0.33-1.65)$ \\
\hline & Acetic acid derivatives & $1143 / 956$ & $88 / 59$ & $0.76(0.50-1.15)$ & $36 / 19$ & $0.61(0.31-1.20)$ \\
\hline & Propionic acid derivatives & $954 / 781$ & $224 / 197$ & $0.84(0.64-1.09)$ & $89 / 56$ & $0.64(0.43-0.95)$ \\
\hline & NSAID others & $1229 / 1004$ & $27 / 27$ & $1.27(0.66-2.42)$ & $11 / 3$ & - \\
\hline \multirow[t]{5}{*}{$\mathrm{BMl}<25$} & NSAID (all) & $578 / 537$ & $233 / 183$ & $0.78(0.58-1.04)$ & $131 / 99$ & $0.65(0.45-0.94)$ \\
\hline & Aspirin & $901 / 794$ & $32 / 22$ & $0.84(0.43-1.63)$ & $9 / 3$ & - \\
\hline & Acetic acid derivatives & $883 / 783$ & $44 / 22$ & $0.40(0.20-0.77)$ & $15 / 14$ & $1.16(0.42-3.15)$ \\
\hline & Propionic acid derivatives & $656 / 575$ & 191/163 & $0.89(0.66-1.21)$ & $95 / 81$ & $0.80(0.52-1.22)$ \\
\hline & NSAID others & 919/806 & $14 / 11$ & $1.51(0.56-4.06)$ & $9 / 2$ & - \\
\hline \multirow[t]{5}{*}{$\mathrm{BMI}>25$} & NSAID (all) & $593 / 574$ & $251 / 262$ & $0.84(0.65-1.08)$ & $124 / 81$ & $0.61(0.43-0.86)$ \\
\hline & Aspirin & $907 / 859$ & $47 / 48$ & $1.10(0.68-1.80)$ & $14 / 10$ & $0.74(0.30-1.82)$ \\
\hline & Acetic acid derivatives & $871 / 837$ & $69 / 64$ & $0.94(0.61-1.44)$ & $28 / 16$ & $0.54(0.27-1.10)$ \\
\hline & Propionic acid derivatives & $695 / 657$ & 189/201 & $0.85(0.64-1.12)$ & $84 / 59$ & $0.64(0.43-0.95)$ \\
\hline & NSAID others & $943 / 891$ & $19 / 24$ & $1.44(0.71-2.95)$ & $6 / 2$ & - \\
\hline
\end{tabular}

$O R$ Odds ratio adjusted for age, recruitment area, education level, tobacco smoking history, $B M I$ family history of breast cancer, number of deliveries, age at first delivery, menarche age, and menopausal status. Cl confidence interval

their usefulness, whatever their effect on breast cancer might be.

On the other hand, COX inhibition would reduce aromatase activity [44]. Peripheral aromatization of fatty acids is known to be largely responsible for estrogen production in postmenopausal women -in whom adipose tissue represents an important local source of estrogen-; therefore, regulation of aromatase synthesis in the breast could be particularly important in postmenopausal breast cancer [45]. Reducing aromatase activity via COX inhibition could also explain, at least partially, the decrease in breast cancer incidence linked to NSAID use [8], since COX inhibition would reduce estrogen concentration in the breast, restricting the growth of estrogen-dependent tumors.

This study has several limitations. First, NSAID consumption was self-reported, which could introduce a recall bias. For a recall bias to be responsible for the protective effects reported here, the bias would have to be differential in cases and controls, with controls remembering their previous NSAID consumption better; this seems counterintuitive as one would expect cases to be more motivated for remembering their previous exposures. In addition, if cases are less prone to report their NSAID usage, the same bias would be expected in all NSAID groups and in each stratum analyzed; however, our results were different according to the type of NSAID, which seems to contradict such a bias. Moreover, in order to minimize a differential recall bias, interviewers were blinded to the case-control status of the participants. Second, although our intention was to record data on aspirin dosage, most patients did not provide sufficiently detailed data on dosages of aspirin or other NSAID use. This fact prevents us from analyzing the dose-effect relationship. Third, we have adjusted for the usual confounders but residual confounding cannot be ruled out. Finally, any case-control study could be 
Table 5 Relationship between consumption of non-steroideal anti-inflammatory drugs and breast cancer, according to tumor characteristics

\begin{tabular}{|c|c|c|c|c|c|c|}
\hline Variable & Category & NSAID & $\begin{array}{l}\text { Unexposed } \\
\text { controls/cases (n) }\end{array}$ & $\begin{array}{l}\text { Exposed } \\
\text { controls/cases (n) }\end{array}$ & OR (95 \% Cl) & $P$ \\
\hline \multirow[t]{12}{*}{ Clinical stage } & \multirow[t]{6}{*}{$1-2$} & NSAID (all) & $1170 / 696$ & $739 / 404$ & $0.80(0.66-0.97$ & 0.02 \\
\hline & & Aspirin & $1807 / 1047$ & $102 / 52$ & $0.93(0.63-1.38)$ & 0.72 \\
\hline & & Acetic acid derivatives & $1753 / 1025$ & $156 / 74$ & $0.75(0.54-1.06)$ & 0.11 \\
\hline & & Propionic acid derivatives & $1350 / 770$ & $559 / 329$ & $0.90(0.74-1.11)$ & 0.33 \\
\hline & & cox2 inhibitors & 1891/1095 & $18 / 4$ & - & - \\
\hline & & NSAID others & 1861/1072 & $48 / 27$ & $1.07(0.61-1.90)$ & 0.81 \\
\hline & \multirow[t]{6}{*}{$3-4$} & NSAID (all) & $1170 / 136$ & $739 / 68$ & $0.74(0.51-1.06)$ & 0.10 \\
\hline & & Aspirin & 1807/192 & $102 / 12$ & $1.31(0.66-2.59)$ & 0.44 \\
\hline & & Acetic acid derivatives & $1753 / 190$ & $156 / 14$ & $0.99(0.53-1.83)$ & 0.97 \\
\hline & & Propionic acid derivatives & $1350 / 147$ & $559 / 57$ & $0.84(0.57-1.24)$ & 0.39 \\
\hline & & cox2 inhibitors & $1891 / 204$ & 18/0 & - & - \\
\hline & & NSAID others & $1861 / 201$ & $48 / 3$ & - & - \\
\hline \multirow[t]{12}{*}{ Pathology } & \multirow[t]{6}{*}{ Ductal cancer } & NSAID (all) & $1170 / 835$ & $739 / 454$ & $0.70(0.58-0.84)$ & $<0.001$ \\
\hline & & Aspirin & $1807 / 1225$ & $102 / 64$ & $0.97(0.66-1.41)$ & 0.86 \\
\hline & & Acetic acid derivatives & $1753 / 1204$ & $156 / 85$ & $0.76(0.55-1.06)$ & 0.11 \\
\hline & & Propionic acid derivatives & 1350/918 & $559 / 371$ & $0.78(0.64-0.95)$ & 0.01 \\
\hline & & cox2 inhibitors & $1891 / 1289$ & $18 / 3$ & - & - \\
\hline & & NSAID others & $1861 / 1259$ & $48 / 30$ & $1.06(0.60-1.87)$ & 0.85 \\
\hline & \multirow[t]{6}{*}{ Non-ductal cancer } & NSAID (all) & $1170 / 151$ & 739/83 & $0.82(0.58-1.15)$ & 0.25 \\
\hline & & Aspirin & $1807 / 228$ & $102 / 6$ & $0.50(0.21-1.19)$ & 0.12 \\
\hline & & Acetic acid derivatives & $1753 / 219$ & $156 / 15$ & $0.85(0.46-1.58)$ & 0.61 \\
\hline & & Propionic acid derivatives & $1350 / 166$ & $559 / 68$ & $0.91(0.63-1.31)$ & 0.60 \\
\hline & & cox2 inhibitors & $1891 / 234$ & $18 / 0$ & - & - \\
\hline & & NSAID others & $1861 / 232$ & $48 / 2$ & - & - \\
\hline \multirow[t]{18}{*}{ Inmunohistochemistry } & \multirow[t]{6}{*}{ Hormone +} & NSAID (all) & $1170 / 727$ & $739 / 390$ & $0.72(0.60-0.88)$ & $<0.001$ \\
\hline & & Aspirin & $1807 / 1069$ & $102 / 48$ & $0.82(0.55-1.24)$ & 0.35 \\
\hline & & Acetic acid derivatives & $1753 / 1044$ & $156 / 73$ & $0.76(0.54-1.08)$ & 0.12 \\
\hline & & Propionic acid derivatives & 1350/805 & $559 / 312$ & $0.80(0.65-0.98)$ & 0.03 \\
\hline & & cox2 inhibitors & $1891 / 1115$ & $18 / 2$ & - & - \\
\hline & & NSAID others & $1861 / 1089$ & $48 / 28$ & $1.28(0.73-2.25)$ & 0.38 \\
\hline & \multirow[t]{6}{*}{ HER2+ } & NSAID (all) & $1170 / 739$ & $172 / 83$ & $0.63(0.45-0.88)$ & 0.007 \\
\hline & & Aspirin & $1807 / 102$ & 244/11 & $0.79(0.38-1.65)$ & 0.53 \\
\hline & & Acetic acid derivatives & $1753 / 238$ & $156 / 17$ & $0.67(0.36-1.24)$ & 0.20 \\
\hline & & Propionic acid derivatives & 1350/188 & $559 / 67$ & $0.66(0.46-0.95)$ & 0.03 \\
\hline & & cox2 inhibitors & $1891 / 255$ & $18 / 0$ & - & - \\
\hline & & NSAID others & $1861 / 251$ & $48 / 4$ & - & - \\
\hline & \multirow{6}{*}{$\begin{array}{l}\text { Triple negative } \\
\text { breast cancer }\end{array}$} & NSAID (all) & $1170 / 94$ & $739 / 63$ & $0.87(0.58-1.30)$ & 0.49 \\
\hline & & Aspirin & $1807 / 148$ & $102 / 9$ & $1.24(0.57-2.71)$ & 0.59 \\
\hline & & Acetic acid derivatives & $1753 / 147$ & $156 / 10$ & $0.86(0.41-1.79)$ & 0.68 \\
\hline & & Propionic acid derivatives & $1350 / 103$ & $559 / 54$ & $0.99(0.64-1.52)$ & 0.95 \\
\hline & & cox2 inhibitors & 1891/156 & 18/1 & - & - \\
\hline & & NSAID others & $1861 / 154$ & $48 / 3$ & - & - \\
\hline
\end{tabular}


Table 6 Relationship between length of non-steroideal anti-inflammatory drug consumption and breast cancer, according to tumor characteristics

\begin{tabular}{|c|c|c|c|c|c|c|c|}
\hline \multirow[t]{2}{*}{ Variable } & \multirow[t]{2}{*}{ Category } & \multirow[t]{2}{*}{ NSAID } & \multirow{2}{*}{$\begin{array}{l}\text { No consumption } \\
\text { Controls/cases } \\
\text { (n) }\end{array}$} & \multicolumn{2}{|c|}{ Consumption $\leq 5 \mathrm{y}$} & \multicolumn{2}{|c|}{ Consumption >5y } \\
\hline & & & & $\begin{array}{l}\text { Controls/cases } \\
\text { (n) }\end{array}$ & OR $(95 \% \mathrm{Cl})$ & $\begin{array}{l}\text { Controls/cases } \\
\text { (n) }\end{array}$ & OR $(95 \% \mathrm{Cl})$ \\
\hline \multirow[t]{10}{*}{ Clinical stage } & \multirow[t]{5}{*}{$1-2$} & NSAID (all) & $1171 / 695$ & $484 / 281$ & $0.85(0.69-1.06)$ & $255 / 123$ & $0.69(0.52-0.92)$ \\
\hline & & Aspirin & 1808/1047 & $79 / 44$ & $1.01(0.65-1.58)$ & $23 / 8$ & $0.74(0.31-1.73)$ \\
\hline & & $\begin{array}{l}\text { Acetic acid } \\
\text { derivatives }\end{array}$ & $1754 / 1025$ & $113 / 53$ & $0.79(0.53-1.17)$ & $43 / 21$ & $0.73(0.38-1.42)$ \\
\hline & & Propionic acid derivatives & $1351 / 770$ & $380 / 234$ & $0.93(0.73-1.17)$ & $179 / 95$ & $0.78(0.57-1.08)$ \\
\hline & & NSAID others & 1862/1072 & $33 / 24$ & $1.56(0.82-2.95)$ & $15 / 3$ & - \\
\hline & \multirow[t]{5}{*}{$3-4$} & NSAID (all) & $1171 / 136$ & $484 / 54$ & $0.85(0.57-1.27)$ & $255 / 14$ & $0.46(0.24-0.88)$ \\
\hline & & Aspirin & 1808/192 & $79 / 11$ & $1.61(0.78-3.34)$ & $23 / 1$ & - \\
\hline & & Acetic acid derivatives & $1754 / 190$ & $113 / 12$ & $1.08(0.54-2.17)$ & $43 / 2$ & - \\
\hline & & Propionic acid derivatives & $1351 / 147$ & $380 / 45$ & $0.91(0.59-1.40)$ & $179 / 12$ & $0.54(0.27-1.09)$ \\
\hline & & NSAID others & $1862 / 201$ & $33 / 3$ & - & $15 / 0$ & - \\
\hline \multirow[t]{10}{*}{ Pathology } & \multirow[t]{5}{*}{ Ductal cancer } & NSAID (all) & $1171 / 835$ & $484 / 324$ & $0.74(0.60-0.91)$ & $255 / 130$ & $0.60(0.45-0.79)$ \\
\hline & & Aspirin & $1808 / 1225$ & $79 / 56$ & $1.09(0.72-1.66)$ & $23 / 8$ & $0.60(0.26-1.41)$ \\
\hline & & Acetic acid derivatives & $1754 / 1204$ & $113 / 64$ & $0.78(0.53-1.14)$ & $43 / 21$ & $0.68(0.36-1.30)$ \\
\hline & & Propionic acid derivatives & $1351 / 918$ & $380 / 270$ & $0.81(0.65-1.02)$ & $179 / 101$ & $0.68(0.49-0.94)$ \\
\hline & & NSAID others & $1862 / 1259$ & $33 / 28$ & $1.42(0.77-2.67)$ & $15 / 2$ & \\
\hline & \multirow[t]{5}{*}{ Non-ductal cancer } & NSAID (all) & $1171 / 151$ & $484 / 50$ & $0.78(0.53-1.15)$ & $255 / 33$ & $0.90(0.55-1.48)$ \\
\hline & & Aspirin & $1808 / 228$ & $79 / 5$ & $0.59(0.23-1.53)$ & $23 / 1$ & - \\
\hline & & Acetic acid derivatives & $1754 / 219$ & $113 / 11$ & $0.92(0.45-1.87)$ & $43 / 4$ & - \\
\hline & & Propionic acid derivatives & $1351 / 166$ & $380 / 40$ & $0.79(0.51-1.22)$ & $179 / 28$ & $1.15(0.67-1.96)$ \\
\hline & & NSAID others & $1862 / 232$ & $33 / 1$ & - & $15 / 1$ & - \\
\hline \multirow{15}{*}{$\begin{array}{l}\text { Inmunohisto- } \\
\text { chemistry }\end{array}$} & \multirow[t]{5}{*}{ Hormone + } & NSAID (all) & $1171 / 727$ & $484 / 267$ & $0.74(0.60-0.92)$ & $256 / 123$ & $0.69(0.52-0.92)$ \\
\hline & & Aspirin & 1808/1069 & $79 / 38$ & $0.85(0.54-1.36)$ & $23 / 10$ & $0.79(0.36-1.75)$ \\
\hline & & $\begin{array}{l}\text { Acetic acid } \\
\text { derivatives }\end{array}$ & $1754 / 1044$ & $113 / 50$ & $0.69(0.46-1.04)$ & $43 / 23$ & $0.94(0.51-1.75)$ \\
\hline & & Propionic acid derivatives & $1351 / 805$ & $380 / 221$ & $0.82(0.65-1.04)$ & 179/91 & $0.76(0.55-1.05)$ \\
\hline & & NSAID others & 1862/1089 & $33 / 25$ & $1.62(0.87-3.01)$ & $15 / 3$ & - \\
\hline & \multirow[t]{5}{*}{ HER2 +/Hormone- } & NSAID (all) & $1171 / 172$ & $484 / 61$ & $0.70(0.48-1.01)$ & $255 / 22$ & $0.49(0.28-0.87)$ \\
\hline & & Aspirin & $1808 / 244$ & $79 / 10$ & $0.89(0.41-1.96)$ & $23 / 1$ & - \\
\hline & & Acetic acid derivatives & $1754 / 238$ & $113 / 16$ & $1.02(0.29-3.60)$ & $43 / 1$ & - \\
\hline & & Propionic acid derivatives & $1351 / 188$ & $380 / 47$ & $0.66(0.43-0.99)$ & $179 / 20$ & $0.61(0.33-1.12)$ \\
\hline & & NSAID others & $1862 / 251$ & $33 / 4$ & - & $15 / 0$ & - \\
\hline & \multirow{5}{*}{$\begin{array}{l}\text { Triple negative } \\
\text { breast cancer }\end{array}$} & NSAID (all) & $1171 / 94$ & $484 / 49$ & $0.94(0.60-1.48)$ & $255 / 14$ & $0.60(0.30-1.17)$ \\
\hline & & Aspirin & $1808 / 148$ & $79 / 9$ & $1.74(0.78-3.89)$ & $23 / 0$ & - \\
\hline & & Acetic acid derivatives & $1754 / 144$ & $113 / 8$ & $0.85(0.36-2.01)$ & $43 / 2$ & - \\
\hline & & Propionic acid derivatives & $1351 / 103$ & $380 / 42$ & $1.04(0.64-1.68)$ & $179 / 12$ & $0.68(0.32-1.43)$ \\
\hline & & NSAID others & $1862 / 154$ & $33 / 2$ & - & $15 / 1$ & - \\
\hline
\end{tabular}

$O R$ odds ratio adjusted for age, recruitment area, education level, tobacco smoking history, $B M I$ family history of breast cancer, number of deliveries, age at first delivery, menarche age, and menopausal status. Cl: confidence interval

affected by a selection bias. Our study is population based, as controls have been selected from the same residence area as cases; the small differences in case and control educational levels suggest that the selection has been adequately carried out. Moreover, the high response rates obtained in this study $(71 \%$ for breast cancer cases and $72 \%$ for controls, respectively) minimize the possibility of occurrence of such bias. 


\section{Conclusions}

Summarizing, although there is increasing evidence for a protective effect of NSAID against breast cancer risk, our results indicate that this effect is more pronounced in postmenopausal women and in estrogen/progesterone + receptor or HER2+ cancers. As this effect seems to be moderate, concerns remain about whether NSAID may play a role in chemoprevention or just indicate a pathway for identifying further more specific drugs that could be used for breast cancer chemoprevention in high risk women.

\section{Additional files}

Additional file 1: Table S1. Relationship between NSAID consumption and breast cancer according to COX2/COX1 selectivity and women's characteristics (DOC $34 \mathrm{~kb}$ )

Additional file 2: Table S2. Relationship between NSAID consumption and breast cancer according to COX2/COX1 selectivity and tumor characteristics (DOC $39 \mathrm{~kb}$ )

\section{Acknowledgements}

Not applicable.

\section{Funding}

The study was partially funded by the "Accion Transversal del Cancer" approved by the Spanish Council of Ministers on the 11th October 2007, by the Instituto de Salud Carlos III-FEDER (PI08/1770, PI08/0533, PI08/1359, PI09/ 00773-Cantabria, PI09/01286-León, PI09/01903-Valencia, PI09/02078-Huelva, PI09/01662-Granada, PI11/01403, PI11/01889-FEDER, PI11/00226, PI11/01810, PI11/02213, PI12/00488, PI12/00265, PI12/01270, PI12/00715, PI12/00150, PI14/01219, PI15/00069), by the Fundación Marqués de Valdecilla (API 10/09), by the ICGC International Cancer Genome Consortium CLL (The ICGC CLL-Genome Project is funded by Spanish Ministerio de Economía y Competitividad (MINECO) through the Instituto de Salud Carlos III (ISCIII) and Red Temática de Investigación del Cáncer (RTICC) del ISCIII (RD12/0036/0036)), by the Junta de Castilla y León (LE22A10-2), by the Consejería de Salud of the Junta de Andalucía (2009-S0143), by the Conselleria de Sanitat of the Generalitat Valenciana (AP_061/10), by the Recercaixa (2010ACUP 00310), by the Regional Government of the Basque Country, by the European Commission grants FOOD-CT-2006-036224-HIWATE, by the Spanish Association Against Cancer (AECC) Scientific Foundation and by the Catalan Government DURSI grant 2009SGR1489.

\section{Availability of data and materials}

The datasets generated during and/or analysed during the current study are not publicly available because the informed consent signed by all participants explicitly excludes the authorization for sharing data.

\section{Authors' contributions}

TDS, IGA, MdP and JL contributed substantially to the conception, design and acquisition of data. TDS, IGA and JL contributed to the analysis and interpretation of the data. TDS, IGA, MP and $J$ contributed to devising the draft of the article. The remaining authors (BPG, SS, VM, PA, TFV, AB, AT, MDS, RPP, RMG, VL, EGL, MHA, MJME, MG, GCV, NA, MK and MP) participated in the patients' recruitment, acquisition of data and critical revision of the manuscript. All authors approved the final version to be published.

Authors' information

Not applicable.

\section{Competing interests}

The authors declare that they have no competing interests.

\section{Ethics approval and consent to participate}

This study was approved by the corresponding ethics committee of each area (Comité ético de investigación clínica de Asturias, Barcelona, Cantabria, Girona, Gipuzkoa, Huelva, León, Madrid, Navarra and Valencia) and informed written consent was obtained from parents. The MCC-Spain study also followed the Declaration of Helsinki and the Spanish Personal Data Protection Act of 1999. Informed consent was obtained from all individual participants included in the study. All procedures were performed with the ethical standards of the institutional and/or national research committee and with the 1964 Helsinki declaration and its later amendments or comparable ethical standards.

\section{Author details}

${ }^{1}$ CIBER Epidemiologia y Salud Publica (CIBERESP), Madrid, Spain. ${ }^{2}$ University of Cantabria - IDIVAL, Santander, Spain. ${ }^{3}$ Department of Obstetrics and Gynecology, Nuevo Belén University Hospital, Madrid, Spain. ${ }^{4}$ Cancer and Environmental Epidemiology Unit, National Center for Epidemiology, Carlos III Institute of Health, Madrid, Spain. ${ }^{5}$ Cancer Epidemiology Research Group, Oncology and Hematology Area, IIS Puerta de Hierro (IDIPHIM), Madrid, Spain. ${ }^{6}$ Servei d'Oncologia Mèdica, Hospital del Mar, Barcelona, Spain. ${ }^{7}$ Cancer Research Program IMIM (Hospital del Mar Medical Research Institute), Barcelona, Spain. ${ }^{8}$ Cancer Prevention and Control Program, Catalan Institute of Oncology-IDIBELL, and University of Barcelona, Barcelona, Spain. ${ }^{9}$ Public Health Division of Gipuzkoa, Biodonostia Research Institute, San Sebastian, Spain. ${ }^{10}$ Área de Medicina Preventiva y Salud Pública,

Departamento de Ciencias Biomédicas, Universidad de León, León, España. ${ }^{11}$ Grupo de Investigación en Interacciones Gen-Ambiente y Salud (GIIGAS), Universidad de León, León, España. ${ }^{12}$ Navarra Public Health Institute, Pamplona, Spain. ${ }^{13}$ Navarra Institute for Health Research (IdiSNA), Pamplona, Spain. ${ }^{14}$ IUOPA, Universidad de Oviedo, Oviedo, Spain. ${ }^{15}$ Universidad de Huelva, Huelva, Spain. ${ }^{16}$ Centro de Investigación en Salud y Medio Ambiente (CYSMA), Huelva, Spain. ${ }^{17}$ Area de Cáncer y Salud Pública, Fundación FISABIO- Salud Pública, Valencia, Spain. ${ }^{18}$ Epidemiology Unit and Girona Cancer Registry, Oncology Coordination Plan, Department of Health, Autonomous Government of Catalonia and Descriptive Epidemiology, Genetics and Cancer Prevention Group [Girona Biomedical Research Institute (IdIBGi)], Catalan Institute of Oncology, Girona, Spain. ${ }^{19}$ Centre for Research in Environmental Epidemiology (CREAL), Barcelona, Spain. ${ }^{20}$ Universitat Pompeu Fabra (UPF), Barcelona, Spain. ${ }^{21}$ Onkologikoa- Oncology Institute Gipuzkoa, San Sebastian, Spain. ${ }^{22}$ Sección de Oncología, Complejo Asistencial Universitario de León, León, Spain. ${ }^{23}$ IMIM (Hospital del Mar Medical Research Institute), Barcelona, Spain.

Received: 1 December 2015 Accepted: 9 August 2016

Published online: 20 August 2016

\section{References}

1. Williams CS, Mann M, DuBois RN. The role of cyclooxygenases in inflammation, cancer, and development. Oncogene. 1999;18(55):7908-16.

2. Harris RE, Alshafie GA, Seibert K. Chemoprevention of breast cancer in rats by celecoxib, a cyclooxygenase 2 inhibitor. Cancer Res. 2000;20(8):2101-3.

3. Sharpe CR, Collet JP, MCNutt M, Belzile E, Boivin JF, Hanley JA. Nested case-control study of the effects of non-steroidal anti-inflammatory drugs on breast cancer risk and stage. Br J Cancer. 2000;83(1):112-20.

4. Harris RE, Chlebowski RT, Jackson RD, Frid DJ, Ascenseo JL, Anderson G, Loar A, Rodabough RJ, White E, McTiernan A. Women's Health Initiative. Breast cancer and nonsteroidal anti-inflammatory drugs: prospective results from the Women's Health Initiative. Cancer Res. 2003;63(18):6096-101.

5. Marshall SF, Bernstein L, Anton-Culver H, Deapen D, Horn-Ross PL, Mohrenweiser H, Peel D, Pinder R, Purdie DM, Reynolds P, Stram D, West D, Wright WE, Ziogas A, Ross RK. Nonsteroidal anti-inflammatory drug use and breast cancer risk by stage and hormone receptor status. J Natl Cancer Inst. 2005;97(11):805-12.

6. Rosenberg L. Nonsteroidal anti-inflammatory drugs and cancer. Prev Med. 1995;24(2):107-9.

7. Coogan PF, Rao SR, Rosenberg L, Palmer JR, Strom BL, Zauber AG, Stolley PD, Shapiro S. The relationship of nonsteroidal anti-inflammatory drug use to the risk of breast cancer. Prev Med. 1999:29(2):72-6.

8. Rahme E, Ghosn J, Dasgupta K, Rajan R, Hudson M. Association between frequent use of nonsteroidal antiinflammatory drugs and breast cancer. BMC Cancer. 2005;5:159. 
9. de Pedro M, Baeza S, Escudero MT, Dierssen-Sotos T, Gomez-Acebo I, Pollan $\mathrm{M}$, Llorca J. Effect of COX-2 inhibitors and other non-steroidal inflammatory drugs on breast cancer risk: a meta-analysis. Breast Cancer Res Treat. 2015;149:525-36.

10. Harris RE, Beebe-Donk J, Alshafie GA. Reduction in the risk of human breast cancer by selective cyclooxygenase-2 (COX-2) inhibitors. BMC Cancer. 2006;6:27.

11. Ashok V, Dash C, Rohan TE, Sprafka JM, Terry PD. Selective cyclooxygenase-2 (COX-2) inhibitors and breast cancer risk. Breast. 2011;20(1):66-70.

12. Vinogradova Y, Coupland C, Hippisley-Cox J. Exposure to cyclooxygenase-2 inhibitors and risk of cancer: nested case-control studies. Br J Cancer. 2011;105(3):452-9.

13. Castaño-Vinyals $\mathrm{G}$, et al. Population-based multicase-control study in common tumors in Spain (MCC-Spain): rationale and study design. GaC Sanit. 2015;29(4):308-15.

14. WHO Collaborating Centre for Drug Statistics Methodology. 2015. http://www.whocc.no/atc_ddd_index/. Accessed: 5 May, 2015.

15. Warner TD, Giuliano F, Vojnovic I, Bukasa A, Mitchell JA, Vane JR. Nonsteroid drug selectivities for cyclo-oxygenase-1 rather than cyclo-oxygenase-2 are associated with human gastrointestinal toxicity: A full in vitro analysis. Proc Natl Acad Sci U S A. 1999;96:7563-8.

16. Harris R, Namboodiri K, Farrar W. Epidemiologic-study of nonsteroidal antiinflammatory drugs and breast-cancer. Oncol Rep. 1995;2(4):591-2.

17. Harris RE, Namboodiri KK, Farrar WB. Nonsteroidal antiinflammatory drugs and breast cancer. Epidemiology. 1996;7(2):203-5.

18. Cotterchio M, Kreiger N, Sloan M, Steingart A. Nonsteroidal antiinflammatory drug use and breast cancer risk. Cancer Epidemiol Biomarkers Prev. 2001;10(11):1213-7.

19. Moorman PG, Grubber JM, Millikan RC, Newman B. Association between non-steroidal anti-inflammatory drugs (NSAIDs) and invasive breast cancer and carcinoma in situ of the breast. Cancer Causes Control. 2003;14(10):915-22.

20. Swede $H$, Mirand AL, Menezes RJ, Moysich KB. Association of regular aspirin use and breast cancer risk. Oncology. 2005;68(1):40-7.

21. Kirsh VA, Kreiger N, Cotterchio M, Sloan M, Theis B. Nonsteroidal antiinflammatory drug use and breast cancer risk: subgroup findings. Am J Epidemiol. 2007;166(6):709-16.

22. Ou SM, Chen YT, Chao PW, Lee YJ, Liu CJ, Yeh CM, Chen TJ, Chen TW, Yang WC, Li SY. Nonsteroidal anti-inflammatory drug use is associated with cancer risk reduction in chronic dialysis patients. Kidney Int. 2013;84(1):198-205.

23. Harris RE, Namboodiri K, Stellman SD, Wynder EL. Breast cancer and NSAID use: heterogeneity of effect in a case-control study. Prev Med. 1995;24(2):119-20.

24. Langman MJ, Cheng KK, Gilman EA, Lancashire RJ. Effect of anti-inflammatory drugs on overall risk of common cancer: case-control study in general practice research database. BMJ. 2000;320(7250):1642-6.

25. Meier CR, Schmitz S, Jick H. Association between acetaminophen or nonsteroidal antiinflammatory drugs and risk of developing ovarian, breast, or colon cancer. Pharmacotherapy. 2002;22(3):303-9.

26. Zhang Y, Coogan PF, Palmer JR, Strom BL, Rosenberg L. Use of nonsteroidal antiinflammatory drugs and risk of breast cancer: the Case-control Surveillance Study revisited. Am J Epidemiol. 2005;162(2):165-70.

27. Davis S, Mirick DK. Medication use and the risk of breast cancer. Eur J Epidemiol. 2007:22(5):319-25.

28. Cronin-Fenton DP, Pedersen L, Lash TL, Friis S, Baron JA, Sørensen HT. Prescriptions for selective cyclooxygenase-2 inhibitors, non-selective non-steroidal anti-inflammatory drugs, and risk of breast cancer in a population-based case-control study. Breast Cancer Res. 2010;12(2):R15.

29. Harris RE, Kasbari S, Farrar WB. Prospective study of nonsteroidal anti-inflammatory drugs and breast cancer. Oncol Rep. 1999;6(1):71-3.

30. Johnson TW, Anderson KE, Lazovich D, Folsom AR. Association of aspirin and nonsteroidal anti-inflammatory drug use with breast cancer. Cancer Epidemiol Biomarkers Prev. 2002;11(12):1586-91.

31. Gallicchio L, Visvanathan K, Burke A, Hoffman SC, Helzlsouer KJ. Nonsteroidal anti-inflammatory drugs and the risk of developing breast cancer in a population-based prospective cohort study in Washington County, MD. Int J Cancer. 2007;121(1):211-5.

32. Gill JK, Maskarinec G, Wilkens LR, Pike MC, Henderson BE, Kolonel LN. Nonsteroidal antiinflammatory drugs and breast cancer risk: the multiethnic cohort. Am J Epidemiol. 2007;166(10):1150-8.
33. Ready A, Velicer CM, McTiernan A, White E. NSAID use and breast cancer risk in the VITAL cohort. Breast Cancer Res Treat. 2008;109(3):533-43.

34. Gierach GL, Lacey Jr JV, Schatzkin A, Leitzmann MF, Richesson D, Hollenbeck AR, Brinton LA. Nonsteroidal anti-inflammatory drugs and breast cancer risk in the National Institutes of Health-AARP Diet and Health Study. Breast Cancer Res. 2008;10(2):R38.

35. Siemes C, Visser LE, Coebergh JW, Hofman A, Uitterlinden AG, Stricker BH. Protective effect of NSAIDs on cancer and influence of COX-2 C(-765G) genotype. Curr Cancer Drug Targets. 2008;8(8):753-64.

36. Sørensen HT, Friis S, Nørgård B, Mellemkjaer L, Blot WJ, McLaughlin JK, Ekbom A, Baron JA. Risk of cancer in a large cohort of nonaspirin NSAID users: a population-based study. Br J Cancer. 2003;88(11):1687-92.

37. Jacobs EJ, Thun MJ, Connell CJ, Rodriguez C, Henley SJ, Feigelson HS, Patel AV, Flanders WD, Calle EE. Aspirin and other nonsteroidal anti-inflammatory drugs and breast cancer incidence in a large US cohort. Cancer Epidemiol Biomarkers Prev. 2005;14(1):261-4.

38. Friis S, Thomassen L, Sørensen HT, Tjønneland A, Overvad K, Cronin-Fenton DP, Vogel U, McLaughlin JK, Blot WJ, Olsen JH. Nonsteroidal anti-inflammatory drug use and breast cancer risk: a Danish cohort study. Eur J Cancer Prev. 2008;17(2):88-96.

39. Soh JW, Weinstein IB. Role of COX-independent targets of NSAIDs and related compounds in cancer prevention and treatment. Prog Exp Tumor Res. 2003;37:261-85.

40. Grosch S, Maier TJ, Schiffmann S, Geisslinger G. Cyclooxygenase-2 (COX-2)-independent anticarcinogenic effects of selective COX-2 inhibitors. J Natl Cancer Inst. 2006;98:736-47.

41. Harris RE, Casto BC, Harris ZM. Cyclooxygenase-2 and the inflammogenesis of breast cancer. World J Clin Oncol. 2014;5:677-92.

42. Hartmann LC, Lingle W, Frost MH, Shaun D, Maloney RA, Vierkant V, Pankratz S, Tisty T, Degnim AC, Visscher DW. COX-2 expression in atypia: correlation with breast cancer risk. 97th Annual Meeting. Proc Amer Assoc Cancer Res. 2006; 47: Abstract No. 2353

43. Howe LR, Subbaramaiah K, Brown AM, Dannenberg AJ. Cyclooxygenase-2: a target for the prevention and treatment of breast cancer. Endocr Relat Cancer. 2001:8:97-114.

44. Prosperi JR, Robertson FM. Cyclooxygenase-2 directly regulates gene expression of P450 Cyp19 aromatase promoter regions pll, pl.3 and pl.7 and estradiol production in human breast tumor cells. Prostaglandins Other Lipid Mediat. 2006;81:55-70.

45. Bulun SE, Lin Z, Imir G, et al. Regulation of aromatase expression in estrogen-responsive breast and uterine disease: from bench to treatment. Pharmacol Rev. 2005:57:359-83.

\section{Submit your next manuscript to BioMed Central and we will help you at every step:}

- We accept pre-submission inquiries

- Our selector tool helps you to find the most relevant journal

- We provide round the clock customer support

- Convenient online submission

- Thorough peer review

- Inclusion in PubMed and all major indexing services

- Maximum visibility for your research

Submit your manuscript at www.biomedcentral.com/submit
) Biomed Central 